\title{
SOBREPOSIÇÕES DE VOZES NO LIVRO DIDÁTICO DE PORTUGUÊS
}

\author{
Ester Maria de Figueiredo Souza* \\ Lúcia Gracia Ferreira \\ Marcone Araujo Higino ${ }^{* * *}$
}

RESUMO: Este artigo analisa uma proposta de prática de produção textual com o gênero artigo de opinião para o primeiro ano ensino médio do livro didático Português: Linguagens do Programa Nacional do Livro Didático - PNLD, edição 2013. Nossa análise mobiliza a noção de polifonia destacando os direcionamentos enunciativos dos autores do livro para extrair as possíveis sobreposições dos discursos que constituem o percurso de interação verbal na atividade de ensino de português, para afirmar a presença de juízos distintos entre o proposto e o realizado para a realização do produto final: produção textual. Concluímos, destacando a presença de três vozes que se sobrepõem: a do currículo escolar, a do professor e a do estudante, como modalizações especificas que caracterizam posicionamentos discursivos na aula de português.

PALAVRAS - CHAVE: Dialogismo; Livro didático de português; Ensino de português; Polifonia.

\section{Introdução}

As discussões sobre interação verbal na sala de aula, sujeitos e discursos ocupam parte de nossos interesses para tematizar pesquisas no campo da Linguística Aplicada (LA). Esses temas, nas nossas produções, são problematizados na ancoragem da Análise Dialógica do Discurso (ADD) - assim denominada no Brasil os estudos do discurso relativos ao

\footnotetext{
* Doutora em Educação. Líder do Grupo de Pesquisa Linguagem e Educação (GPLEd/CNPq). Professora Plena da Universidade Estadual do Sudoeste da Bahia (UESB). E-mail: efigueiredo@uesb.edu.br

** Doutora em Educação. Pesquisadora do Grupo de Pesquisa Linguagem e Educação (GPLEd/CNPq). Professora Adjunta da Universidade Federal do Recôncavo da Bahia (UFRB). E-mail: luciagferreira@ufrb.edu.br

*** Mestrando em Letras: cultura, educação e linguagens (PPGCEL) pela Universidade Estadual do Sudoeste da Bahia (UESB). Professor da Educação Básica da Rede Estadual de Ensino da Bahia. E-mail: mahigino@hotmail.com
} 
Círculo de Bakhtin ${ }^{1}$, notório pensador russo que solidificou algumas teorizações presentes que atualizam pesquisas sobre interação e sala de aula - em diálogo com a LA.

O pensamento bakhtiniano sustenta a tese de que linguagem é de natureza social, constitui os sujeitos e por eles é constituída. A LA assume essa mesma concepção, explorando, ainda, a constituição identitária dos sujeitos em suas práticas discursivas. O espaço escolar e, especificamente, o da sala de aula, é composto por enunciados sobrepostos que (re) constróem identitariamente os sujeitos professor e aluno. Para Faraco (2009):

Nossos enunciados emergem - como respostas ativas que são no diálogo social - da multidão das vozes interiorizadas. Eles são, assim, heterogêneos. Desse ponto de vista, nossos enunciados são sempre discurso citado, embora nem sempre percebidos como tal, já que são tantas as vozes incorporadas que muitas delas são ativas em nós sem que percebamos sua alteridade (na figura bakhtiniana, são palavras que perderam as aspas). (FARACO, 2009, p. 85).

Essa interpretação atende ao nosso propósito de conceber a sala de aula de português como ambiente potente para circulação de discursos, seja por meio dos enunciados que se reverberam no uso e exploração do livro didático pela ação pedagógica do professor(a), seja pelos próprios enunciados do professor(a), aluno(a)(s), como enunciadores do fluxo didático da interação verbal da aula.

Sobre a natureza discursiva do Livro Didático de Português (LDP), Bunzen (2005) o circunscreve como um gênero e destaca a sua composição com o fito de atender as necessidades de trabalho humano em esferas de comunicação social. Os textos, em unidades de ensino e práticas didáticas propostas, tanto ao professor, como expositor dessas, e aos alunos, como respondentes do proposto, visam materializar o currículo escolar e suas intencionalidades.

${ }^{1}$ A expressão Análise Dialógica do Discurso, para Brait (2010) remete à proposta do Círculo de Bakhtin no que tange aos estudos da linguagem e da interação verbal no fluxo ideológico das produções discursivas na sociedade. (BRAIT, 2010). 
Segundo Bunzen (2005, p. 27) o gênero LDP procura, na medida do possível “[...] refletir as condições específicas e as finalidades de cada uma das suas esferas de origem e de circulação”. Outras pesquisas, como Rojo e Batista (2005), indicam a tomada de posição da comunidade científica para se conceber o livro didático como um objeto de investigação, tendo em vista que a sua produção, criação e circulação envolvem diferentes dimensões culturais, econômicas, sociais, políticas, não só educacionais, alertando que se não deve toma-lo, apenas, como um recurso ou suporte de textos. Também, Souza e Ayres (2015) processam a análise do LDP a partir das noções do dialogismo e da réplica do círculo bakhtiniano, para afirmar esse objeto como mobilizador de politica linguística.

Aceitando, pois, que o LDP é constituído por diferentes discursos, atende a situações de ensino e aprendizagem de língua no contexto didático, acolhemos a tese de que esse é um gênero escolar e nos propomos analisar a proposta de trabalho relativa à exploração do artigo de opinião, como um conjunto de enunciados que intercala e sobrepõe-se a outros enunciados, quando do seu funcionamento em uma atividade integrante de LDP Português: Linguagens, atribuída autoria a William Roberto Cereja e Thereza Cochar Magalhães, pertencente ao Programa Nacional do Livro Didático - PNLD.

A prática de produção textual é o propósito da unidade destacada com o artigo de opinião e aborda a questão das cotas para ingresso no ensino superior. Nosso propósito é o de destacar os direcionamentos enunciativos dos autores do LDP para extrair as possíveis sobreposições dos discursos que constituem o percurso de interação verbal na atividade de ensino de português.

Aportaremos na noção de polifonia do círculo bakhtiniano pata afirmar que o LDP incorpora discursos de outras esferas (jornalística, acadêmica, científica, escolar etc.), os quais estarão presentes nas aulas de língua portuguesa, em especial, a partir da atividade analisada, vez que essa cumpre uma função dialógica, pois, o sua estruturação, a partir de um planejamento prévio, atendeu a intenções dos autores, do projeto editorial da obra, a fim de persuadir professor e alunos, o que na análise de Bunzen (2005), sintetiza uma relação dialógica: 
[...] podemos afirmar que as formas que o LDP vai adquirindo, se levarmos em consideração a relação gênero/atividade humana, são resultantes das concepções sobre as atividades de ensino e aprendizagem formal e sobre seus agentes (professores e alunos). É uma relação dialógica que se instaura entre a seleção de objetos de ensino e sua apresentação, levando em consideração determinados interlocutores e determinadas concepções de ensino-aprendizagem. (BUNZEN, 2005, p. 42-43).

O livro didático Português: Linguagens é um exemplar que organiza uma situação sócio comunicativa no contexto de ensino e, a nosso ver, tende a revelar enunciados em gêneros do discurso, (BAKHTIN, 2003):

O emprego da língua efetua-se em forma de enunciados*(orais e escritos) concretos e únicos, proferidos pelos integrantes desse ou daquele campo da atividade humana. Esses enunciados refletem as condições específicas e as finalidades de cada referido campo não só pelo seu conteúdo ( temático) e pelo estilo de linguagem, ou seja, pela seleção dos recursos lexicais, fraseológicos e gramaticais da língua mas, acima de tudo, por sua construção composicional [...] cada campo de utilização da língua elabora seus tipos relativamente estáveis de enunciados, os quais denominamos gêneros do discurso. (BAKHTIN, 2003, p. 261-262).

Um dos ambientes de confronto dialógico por natureza é a sala de aula e para Souza e Coelho (2012):

A sala de aula é um microcosmo da sociedade onde alunos iniciam suas carreiras ainda crianças, desenvolvem-se cognitivamente e se instituem sujeitos sociais, o que fazem à medida que reconhecem seus papéis e funções interacionais nesse espaço institucional. Tudo isso ocorre no entorno da palavra que nem sempre tem vistas ao objeto de ensino e aprendizagem. (SOUZA; COELHO, 2012, p.4). 
Na escola temos o livro didático como instrumento pedagógico por excelência. Em sua constituição, há inúmeras inserções de juízos e valores que reforçam uma ou mais ideais. Sob a mesma ótica, podemos pensar que há apagamentos, silenciamentos e outros movimentos com o objetivo de sustentar visões hegemônicas da sociedade. Desse modo, entende-se que negligenciar vozes e por vezes "gritos" advindos de múltiplos lugares fragilizados de nossa sociedade é omitir e, também, fugir dos necessários embates de nosso grupo social. Os incontáveis veículos de comunicação irradiam valores e posicionamentos construídos a partir de determinados ideais. Estes são elementos que contribuem para ajustar a formação de indivíduos de acordo com o interesse do poder vigente.

\section{As (dis)sonantes vozes do livro didático na aula de português}

O papel centralizador do livro didático é apontado como justificativa homogeneizadora para o ensino. Contudo, apostamos que a ação pedagógica do professor e sua formação assentada nas contribuições da Linguística Aplicada, como também, no aporte teórico das noções de dialogia do pensamento bakhtiniano, perspectivam outras maneiras para o tratamento dos objetos de ensino e aprendizagem de língua(s), recursos e materiais didáticos.

O LDP ressoa vozes dos autores, tidos como organizadores da obra, dos autores dos textos nele dispostos, dos sujeitos alunos e professores, enfim, é um circuito discursivo em potência, não apenas dos enunciadores mais imediatos, como também de outros contextos que se atualizam, quando de sua exploração na aula. É um jogo discursivo, como uma produção prévia definição, tendo em vista que é destinado ao uso pedagógico pelo professor, para orientar suas práticas de ensino de língua, em contexto social que acolhe o LDP como um fator preponderante para a dinâmica discursiva da aula.

Bubnova (2011), tematizando a noção de polifonia em Bakhtin, argumenta sobre a presença de vozes para a composição dos discursos. Essas múltiplas vozes, a seu ver:

[...] são construtoras do sentido de nossas enunciações por nos incitar à resposta, não necessariamente agressões a nosso ser. Para forjar 
um novo sentido a partir das vozes alheias, envolvemo-nos em um processo de compreensão do que se disse antes e tratamos de ouvir a possível resposta de nossos interlocutores, antecipando-a. Todas as palavras são direcionadas a alguém e são de alguém (não há palavras neutras, que escutam por conta própria), e dizer palavras próprias - as que "pertencem" a alguém - só é possível em resposta a algo que foi dito antes de nós. É no processo de comunicação verbal, da interação com o outro, que alguém se faz sujeito forjando seu próprio eu. O “eu” só existe na medida em que está relacionado a um "tu": "Ser significa comunicar-se", e um "eu" é alguém a quem se dirigiu como um "tu”. (BUBNOVA, 2011, p. 271).

Esse jogo de vozes permanece (re) afirmando valores, segue dando manutenção a outros discursos em maior ou menor grau. O ambiente da sala de aula pressupõe o reconhecimento de alguns papéis discursivos desempenhados pelos sujeitos professor e alunos. A hierarquia didática confere certos ritos ao desenvolvimento da aula. Com o repensar das práticas docentes, as instituições de ensino foram provocadas a conceber novas formas para o gerenciamento da atenção e interação didática em sala de aula. A construção dialógica da aula e o domínio da palavra emergem de múltiplas implicações em relação ao contexto social. Souza e Coelho (2012) reforçam que:

[...] Todas as ações em torno da palavra estão submetidas a forças que se opõem: a uma dialogia de forças. A palavra (i) institui movimentos sociais (processo de enunciação) sendo, ao mesmo tempo, por eles determinada (produto enunciativo); (ii) apresenta-se simultaneamente como interrogação (produção de sentido) e réplica (efeito de sentido); e (iii) reitera e ratifica ideologias (discursos). (SOUZA; COELHO, 2012, p.2).

Essa heterogeneidade discursiva presente na sala de aula, explicitada nas tomadas de posição do professor/a e do(s) aluno(s), pelas vozes sociais que reagem de distintas formas, sendo que [...] "Algumas entrarão como vozes de autoridade e outras como vozes internamente persuasivas..." (FARACO, 2009, p. 84), compõem o rito de desenvolvimento da interação verbal de natureza didática da aula de português. Desse modo, esse movimento contínuo de (re) construção na/da interação em sala de aula perpassa tais processos. Dialogamos, aqui com as palavras de Bakhtin (1998): 
[...] a linguagem é grandemente pluridiscursiva. Deve-se isso à coexistência de contradições sócio-ideológicas entre presente e passado, entre diferentes épocas do passado, entre diversos grupos sócio-ideológicos, entre correntes, escolas, círculos, etc.,. Estes "falares" do plurilingüismo entrecruzam-se de maneira multiforme, formando novos "falares" socialmente típicos. (BAKHTIN, 1998, p.98).

Assumimos, então, posicionamentos discursivos que denunciam nossas crenças, valores e juízos perante o objeto do discurso referenciado. A sala de aula de português, como contexto polifônico, é um terreno arenoso, no qual se infiltra as (dis)sonantes vozes para se explorar os fenômenos da polifonia discursiva no e entre os materiais e recursos de ensino.

\section{O livro em funcionamento discursivo no gênero artigo de opinião}

O livro didático Português Linguagens é uma das obras aprovadas pelo Programa Nacional do Livro Didático (PNLD), do Ministério da Educação do Brasil. Desde a sua implementação, como politica linguística, é de distribuição gratuita para as escolas públicas em todo o território nacional. Na sua última edição, neste ano 2017, a referida obra também logrou aprovação. O volume aqui analisado é o do primeiro ano do ensino médio, do ano de 2013. As imagens que ilustram este artigo compõem a exploração do gênero artigo de opinião.

A primeira edição da obra é a do ano de 2010 e é assinada por William Roberto Cereja e Thereza Cochar Magalhães tendo sido aprovada, pela primeira vez pelo PNLD em 2012. De acordo com o Guia de Livros Didáticos um dos pontos fortes desse livro didático é "a exploração pertinente de textos de diferentes linguagens” (BRASIL, 2011, p. $53)$.

Por ser uma obra vinculada ao PNLD, essa se submeteu a critérios prévios para seleção, assim sua adoção, enquanto obra recomendada para todas as escolas públicas do Brasil, sem dúvida, é um auxílio aos professores e, talvez, um das oportunidades que o 
estudante pobre encontra de ter em mãos um conjunto de textos verbo visuais, como ferramenta facilitadora para a sua aprendizagem. Contudo, nisso mesmo reside sua ambiguidade: como se organiza em unidade e unifica a escolha, confere ao currículo escolar abstração e predomínio de padrões de linguagem, que privilegia determinadas questões sociais, construções discursivas e conteúdos em detrimento de outros.

Ao longo de todo o exemplar pode-se constatar nos direcionamentos apresentados pelos autores o modo como deve ser trabalhada a unidade didática, a presença de vozes de outros sujeitos, como autores de textos, editores, organizadores e múltiplos participantes desse gênero do discurso. Tal constatação é reforçada pela avaliação do livro, expressa no Guia de Livros Didáticos:

[...] a coletânea de textos é representativa da diversidade da cultura brasileira e é de interesse do jovem, oferecendo-lhe, assim, experiências significativas de leitura. As atividades colaboram para a formação de um leitor crítico, capaz de lidar com diferentes perspectivas de leitura. (BRASIL, 2011, p. 54).

Com base na compreensão de polifonia, como inserida no princípio dialógico da linguagem concebido por Bakhtin e seu Círculo, consideramos os livro didáticos (de português) como obras essencialmente polifônicas, constituída por variados e diferentes tipos de textos que circulam tanto no interior da escola, como em outros espaços sociais. Esses textos, ao serem inseridos no LDP e utilizados como recursos para o ensino, entrecruzam visões de mundo e assumem uma natureza didática para sua exploração, ou seja, são tratados como objetos de ensino com direcionamentos docentes aos exercícios propostos.

Assim como os textos, também os enunciados direcionados ao professor expressam vozes, implícitas do trabalho proposto para a interpretação e produção textual nas aulas, assim, essa polifonia de vozes não é restrita ao proposto, mas se alarga às vozes que são sugeridas ao professor, às respostas já indicadas às questões e aos modos de como apresentar temáticas. De modo geral, a voz da obra conflui e camufla com a dos organizadores/autores, a do professor, a do aluno(s). 
A atividade de produção textual com o artigo de opinião é estimulada a partir de sugestões ao professor de como se dirigir à turma e aproximar a construção de sentido do texto com o universo cultural dos alunos. As figuras $n^{\circ} 01$ e $n^{\circ} 02$ ilustram essa afirmação, quando na primeira questão interpretativa, se destacam as respostas pretendidas pelo professor.

Figura n ${ }^{\circ} 01$ - Final do Texto e Questões

que se thes oferece. Mas o triste é serem massa de manobra para um populismo interesseiro, vitimas de desinformação e de uma visão estreita, que os deixa em má posiçẩo. Nẫo entran na universidade por mérito pessoal e pelo apoio da familia, mas pelo que o governo, melancolicamente, considera defieiência: a raça ou a escola de onde vieram - esta, aliís, oferecida pelo próprio governo.

Lamento essa trapalhada que prejudica a todos: os que são oficialmente considerados menos capacitados, e por isso recebem o pirulito do favorecimento, e os que ficam chupando o dedo da frustraçẫo, năo importando os anos de estudo, a batalha dos pais e seu mérito pessoal. Meus pêsames, mais uma vez, à educaçẫo brasileira.

Veje, ne 2046)

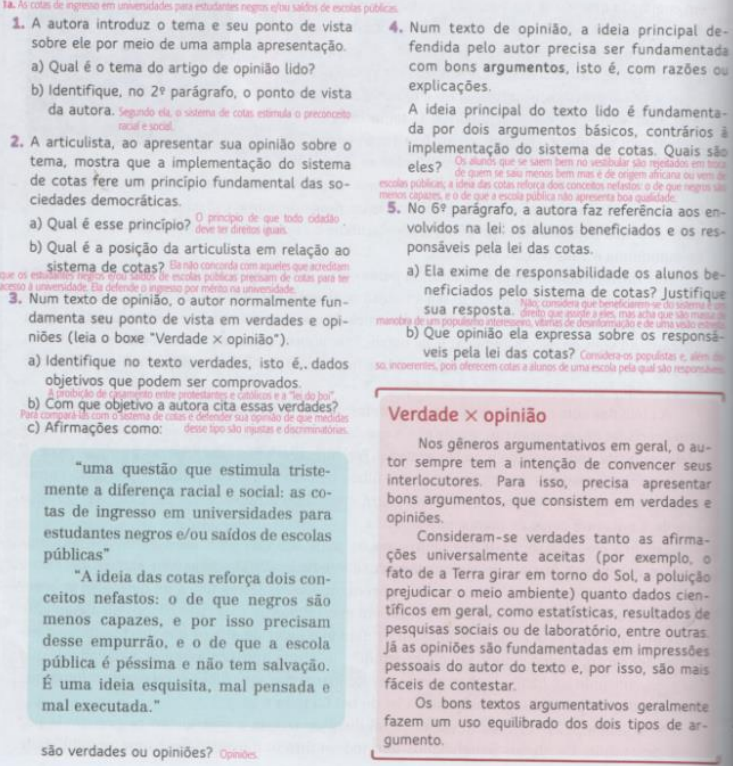

Fonte: CEREJA e MAGALHÃES, 2013, p. 348 
Figura n ${ }^{\circ} 02-$ Final do Texto e Questões

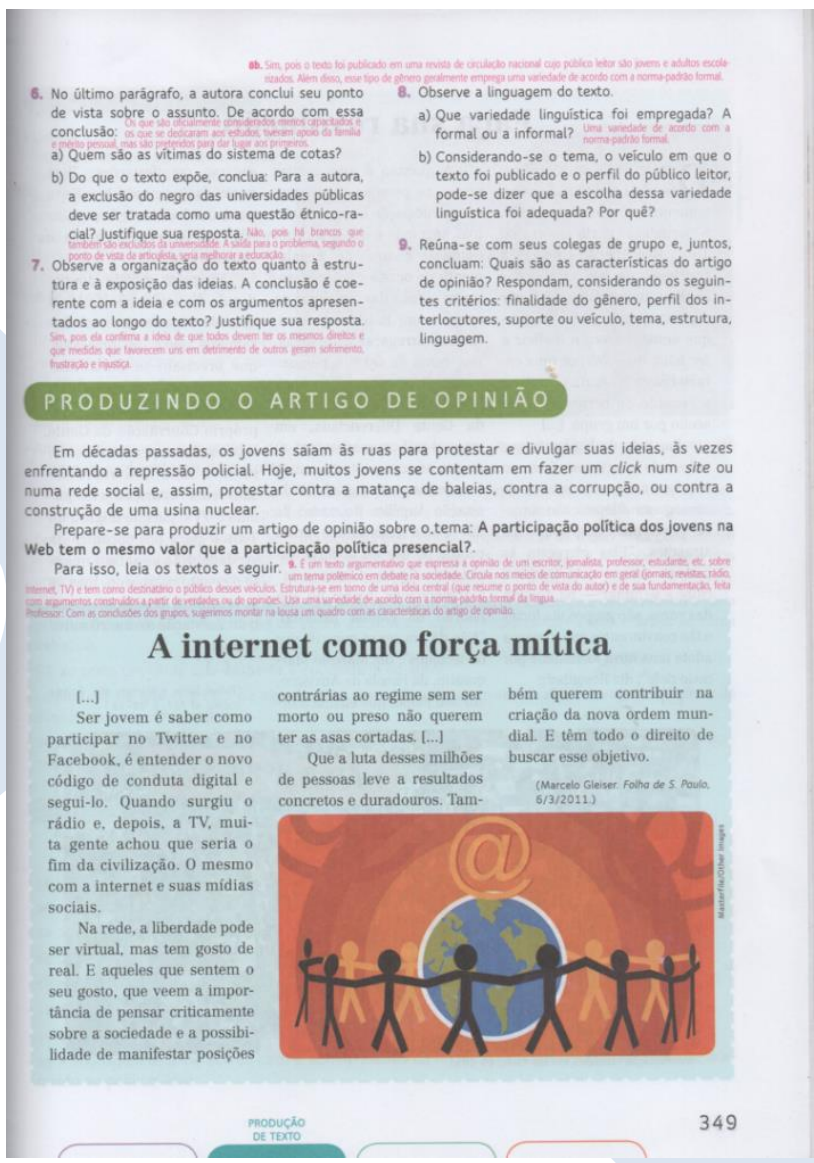

Fonte: CEREJA e MAGALHÃES, 2013, p. 349

O texto que orienta as questões para a realização do produto final produção textual, prática de ensino de língua portuguesa, é o artigo Cotas: o justo e o injusto ${ }^{2}$, de autoria de Lya Luft. A autora qualifica a questão do sistema de cotas contrapondo que o "[...] tema libera 
muita verborragia populista [...]" e convoca outras etnias de brancos de nacionalidades “[... ]portuguesa, italiana, polonesa, alemão ou o que for [... “ ( destaque nosso) para aproximar o seu argumento, ou seja a sua voz, à do leitor estudante, como se ilustra no destaque que transcrevemos do texto proposto para o desenvolvimento da atividade no LDP:

[...] muito se fala em questão que estimula tristemente a diferença racial e social: as cotas de ingresso em universidades [...] O tema libera muita verborragia populista e burra, produz frustação e hostilidade. Instiga o preconceito racial e social [...] E os outros? Os pobres brancos, os remediados de origem portuguesa, italiana, polonesa, alemã ou o que for [...]. É uma ideia esquisita, mal pensada e mal executada [...]. Nem todos os envolvidos nessa nova lei discriminatório e injusta são responsáveis por esse desmando [...]. Mas o triste é serem massa de manobra para um populismo interesseiro [...].Lamento essa trapalhada que prejudica a todos: os que são oficialmente considerados menos capacitados. (CEREJA e MAGALHÃES, 2013, p. 347-348).

Compreender significa tomar uma posição em relação ao enunciado do outro, cuja forma se estabelece através de uma resposta. A produção textual pretendida a partir da interpretação do artigo de opinião é dependente da assunção desse posicionamento pelo leitor. A resposta pretendida é materializada a partir dos enunciados praticados pelos professores, quando do uso do LDP na aula. Caso o professor não detenha conhecimento e domínio da presença polifônica na aula, pode-se confirmar que o mesmo ressoará a voz do autor do LDP.

Bortolotto (2007), ao se debruçar sobre o ensino de português a partir de concepção sócio interacionista da linguagem, indica que

[...] as práticas discursivas da memória pedagógica, na medida em que têm uma história legitimada, revestem-se de certa autoridade quanto à compreensão da realidade objetiva da tradição, associada em muitos aspectos a valores axiológicos positivos. Por isso - mas não só por isso - sem a ação intensa dos docentes relativa ao conhecimento do processo da produção e dos produtos da esfera científica, ou seja, da ação intensa e responsável sobre o objeto de ensino ("ativismo"), o agir pode se tornar um agir-função, uma atividade sem a visão de direção e de profundidade. 
Vemos, portanto, que os sentidos construídos nesse contexto que é o da pedagogia da Língua Portuguesa se dão nas fronteiras entre o que esses sujeitos reconhecem e validam como ensino da língua e as propostas que assumem ou possam vir a assumir em seus atos como consequência da reavaliação de suas práticas. Esse embate é constructo do diálogo ininterrupto do qual esses sujeitos fazem parte e ao qual respondem ativamente (ou deveriam responder - questão ética!). Nosso desafio como educadores, acreditamos, é com um discurso intermitente, dialógico entre o dado e o novo. (BORTOLOTTO, 2007, p. 133.)

A atividade proposta ainda reitera tais julgamentos nos exercícios propostos, tanto com enunciados das questões que estão em consonância com as ideias da autora do artigo, quanto aos destaques que os autores do livro didático dão as questões propostas, como também nas respostas que finalizam e reafirmam os argumentos.

Os próprios autores, ao informar, num quadro intitulado "Verdade x Opinião", que "Os bons textos argumentativos geralmente fazem um uso equilibrado dos dois tipos de argumento" (CEREJA e MAGALHÃES, 2013, p. 348), revelam uma tomada de posição em relação à política de cotas. Ora, não foram evidenciadas argumentações favoráveis à utilização das cotas. Não se discute aqui se o posicionamento da autora do artigo presente no livro é mais ou menos justo em nossa sociedade, questiona-se, apenas, o fato de não ter espaço para a voz de outro(s) que apoia(m) esse sistema.

As enunciações realizadas pressupõem uma reação responsiva, uma resposta às questões que direcionam a construção de sentido do texto pelos alunos. Alguns termos da Análise Dialógica do Discurso, além de polifonia, comungam para ampliar a incursão nesse campo discursivo. Atentamos, apenas, para a noção responsividade, réplica, alteridade, ressonância, que podem ser ativadas para mobilizar novas e outras análises. Como nosso intuito foi o de expor a sobreposição de vozes (dis)sonantes na atividade didática, defendemos que o professor, ao se apropriar dessas noções encontrará chaves para reavaliar sua práxis pedagógica e instaurar momentos dialógicos de construção de conhecimento sobre e com a língua. Assim, esperamos! 
Dessa forma, os sujeitos ao veicularem os seus enunciados, trazem consigo suas marcas discursivas e expressam suas tomadas de posição. A interação é construída alteritariamente e a ausência de enunciados divergentes nas questões propostas contribui para o predomínio de um único ponto de vista.

Assim, organizar a ação pedagógica para que se extraiam os implícitos do material discursivo, revelando a presença ou ausência de outras vozes, é privilegiar a dialogia entre os sujeitos ativos na aula: o professor, o aluno, o LDP. Os enunciados que orientam a prática de produção textual na mencionada atividade não estimulam a contraposição de mais de um ponto de vista sobre o tema sistema de cotas. Então, os autores mencionam que: "A autora introduz o tema e seu ponto de vista (...)"A articulista, ao apresentar sua opinião sobre o tema" (...) o autor normalmente fundamenta seu ponto de vista em verdades e opiniões.” (CEREJA e MAGALHÃES, 2013, p. 348, grifo nosso). Tal escolha lexical revela o quanto os autores do livro compreendem que são julgamentos de uma autora e que é natural a existência de variados posicionamentos, mas, estranhamente, não discutem o porquê dessa ausência.

Nesse debate cabe também a reflexão no que diz respeito à formação de professores assentada em uma práxis dialógica, o que requer do docente a constância na reflexão sobre o que se ensina, no quando e o porquê se ensina tal conteúdo do currículo escolar. Nenhum livro didático é "O” material de ensino, sua atualização é dependente da configuração discursiva que o professor imprime para o seu uso na aula, ou seja, da teoria que orienta a sua aplicação e embasa as reelaborações e criações dos gestos didáticos de construção do conhecimento linguístico.

\section{Considerações finais}

Partimos da premissa de que o LDP que serviu como objeto de análise para este texto é altamente polifônico. Essa polifonia não se refere exclusivamente a presença das vozes já destacadas, mas também na sobreposição entre elas e no modo como direcionam o trabalho com o gênero proposto. 
Apesar das várias reformulações de estilo e estrutura pelas quais o livro didático de português já passou, ainda prevalece, em sua composição, uma concepção de língua abstrata e de linguagem naturalizada, associada ao discurso hegemônico da sociedade. Assim, acionar dispositivos da Linguística Aplicada, em diálogo com a Análise Dialógica do Discurso para revelar ideologias presentes nas atividades propostas pelos e nos livros didáticos é uma tarefa a ser pensada para os cursos de formação docente e para as aulas de metodologias de ensino de língua(s).

O LDP, por ser assumido pela maioria dos educadores apenas como um recurso pedagógico de suporte ao ensino e minimizando-se a sua natureza discursiva, se constitui como fonte de legitimidade do saber professoral. Contudo, os horizontes de interpretação dos estudantes e dos docentes se conflitam e esse conflito poderá ser assumido como instância de aprendizagem para se revelar mecanismos discursivos das ideologias presentes nas práticas de ensino. Assim, este texto almejou demonstrar como esse enfrentamento segue pulsante no campo educacional. Como já mencionado, não há conteúdo vivencial ideológico que esteja desvinculado do signo, portanto, por mais que a atividade proposta no livro persiga uma suposta neutralidade, denunciam-se subjetividades e escolhas. Por se tratar de uma obra didática, chancelada por meio de edital público e avaliação, enfatiza-se que a atividade do livro didático em destaque neste texto foi e, em termos, ainda é, um exemplo do que deve ser ensinado nas escolas públicas, pois atende às diretrizes curriculares dos sistemas e revozeiam distintas concepções sobre ensino de português. É necessário, finalmente, salientar que uma obra que se submete ao crivo do PNDL, já traz o viés ideológico de seu processo de criação, produção e circulação, pois atende aos critérios do edital para o qual concorreu e logrou êxito, portanto, há em seu funcionamento discursivo, pelo menos, três vozes que se sobrepõem: a do currículo escolar, a do professor e a do estudante e a essas vozes outros posicionamentos políticos e juízos de valores se expõem. 


\title{
OVERLAPS OF VOICES IN PORTUGUESE TEXTBOOK
}

\begin{abstract}
This article analyzes a proposal of practice of textual production with the genre opinion article for the first year of high school of the Portuguese textbook: Languages by National Program of Didactic Book - PNLD, edition 2013. Our analysis mobilizes the notion of polyphony emphasizing the enunciative directives of the authors of the book to extract the possible overlaps of the speeches that constitute the course of verbal interaction in the activity of teaching Portuguese, to affirm the presence of different judgments between the proposed and the realized for the realization of the final product: textual production. We conclude, highlighting the presence of three overlapping voices: the voice of the school curriculum, the voices of the teacher and the student, as specific modalizations that characterize discursive positions in the Portuguese class.
\end{abstract}

KEYWORDS: Dialogism; Portuguese textbook; Portuguese teaching; Polyphony.

\section{REFERÊNCIAS}

BAKHTIN, M. Questões de literatura e de estética. São Paulo:Unesp/Hucitec, 1998.

. Os gêneros do discurso. In: Estética da criação verbal. $3^{\mathrm{a}}$ ed. São Paulo: Martins Fontes, 2003, p. 277-326.

BORTOLOTTO, N. O sentido da ciência no ato pedagógico: conhecimento teórico na prática social. 2007. 239 f. Tese (Doutorado em Educação) - Programa de Pós-graduação em Educação, Universidade Federal de Santa Catarina, Florianópolis, 2007. Acessado em: https://repositorio.ufsc.br/handle/123456789/90474.

BRASIL. Guia de Livros Didáticos: PNLD 2012: Língua Portuguesa. Ensino Médio. Brasília: MEC/SEF, 2011.

BRAIT, B. Análise e teoria do discurso. In: BRAIT, B. (Org.) Bakhtin: outros conceitos chave. São Paulo: Contexto, 2010.

BUBNOVA, T. Voz, sentido e diálogo em Bakhtin. Bakhtiniana, São Paulo, 6 (1): 268-280, Ago./Dez. 2011. Disponível em http://www.scielo.br/pdf/bak/v6n1/v6n1a16

BUNZEN, C. Livro didático de língua portuguesa: um gênero do discurso. Campinas,

SP:UNICAMP, 2005. Dissertação. (Mestrado em Estudos da Linguagem), do Instituto de Estudos da Linguagem, Universidade Estadual de Campinas, 2005. Disponível em:

http://repositorio.unicamp.br/bitstream/REPOSIP/269229/1/Bunzen\%20Junior, $\% 20$ Clecio $\% 20$ dos $\% 20$ Santos_M.pdf

CEREJA, W. R. ; MAGALHÃES, T. C. Português linguagens, vol.1, $1^{\circ}$ ano do ensino médio. Ensino médio II. São Paulo: Saraiva, 2013. 
FARACO, C. A. Linguagem \& Diálogo. As ideias linguísticas do círculo de Bakbtin. São Paulo: Parábola Editorial, 2009.

ROJO, R H. R.; BATISTA, A. A. G. (orgs.). Livro didático de lingua portuguesa, letramento e cultura da escrita. Campinas, SP: Mercado de Letras, 2003.

SOUZA, E. M.F.; COELHO, F.C. B. Aula de Português: palavras e contra palavras. - Anais do SIELP. Volume 2, Número 1. Uberlândia: EDUFU, 2012. ISSN 2237-8758. Disponível em http://www.ileel.ufu.br/anaisdosielp/wpcontent/uploads/2014/07/volume_2_artigo_126.pdf

SOUZA, E. M. F.; D. J. AYRES, Livro didático de português: encadeamentos dialógicos para uma política linguística implícita. Domínios da lingu@gem. Uberlândia. Minas Gerais. 9 (4): 234-248, Out./Dez. 2015. Disponível em: http://www.seer.ufu.br/index.php/dominiosdelinguagem/article/view/30867/17739

Recebido em: 13/09/2017.

Aprovado em: 27/11/2017 